\title{
Transforming Perioperative Transfusion Rates in Gastrointestinal Cancer Surgery: A Snapshot of Data-Driven Practice Change
}

\author{
Susanne G. Warner, MD \\ Department of Surgery, City of Hope National Medical Center, Duarte, CA
}

I am pleased to comment on the work of Dr. Zuckerman et al. ${ }^{1}$ This study reports decreasing perioperative blood transfusion rates for patients with gastrointestinal malignancies in the Ontario Cancer Registry. The study team, led by Dr. Julie Hallet, reports on province-wide adherence to modern restrictive perioperative transfusion guidelines. ${ }^{2}$ They conclude that red blood cell (RBC) transfusion rates have decreased over time, more markedly in recent years, and they report intentions to further examine the appropriateness of transfusion at a province-wide level.

This study sets several important examples for all those seeking to make large-scale improvements in the quality of surgical oncology. First, this acts as a needs assessment for education in the authors' province and provides evidencebased means of action. This is made possible by a longstanding centralized cancer registry, in addition to centralized tracking of blood distribution. ${ }^{3,4}$ Such centralized registries and resource allocation tracking are essential to wide and equitable dissemination of quality improvement measures. Second, the authors are commended for their responsible research conduct. Namely, they reported their results in accordance with the Strengthening The Reporting of OBservational studies in Epidemiology (STROBE) guidelines, and the REporting of studies Conducted using Observational Routinely-collected health Data (RECORD) statement. ${ }^{5,6}$ Beyond following these reporting guidelines, their nuanced statistical methods were impeccably designed to answer well-defined questions.

(C) Society of Surgical Oncology 2020

First Received: 5 October 2020

Accepted: 16 October 2020;

Published Online: 5 November 2020

S. G. Warner, MD

e-mail: suwarner@coh.org
Moreover, the methods were so well explained that even those of us who are guilty of misusing words such as multivariate, and of overtrusting propensity matched data, could understand the rationale behind the analyses chosen. This Methods section is truly a standard to which we should all aspire in reporting database-derived studies.

This study also gives us a unique glimpse into how practice patterns change over time. The authors did observe a reduction in $\mathrm{RBC}$ transfusions given to patients undergoing surgery for gastrointestinal cancer, from $26.5 \%$ in 2007 to $18.9 \%$ in 2018 . They also found a $14 \%$ relative reduction of likelihood of transfusion in the latter years of the study (2015-2018) across all hospitals and patient characteristics. These Canadian cohort data are consistent with National Surgical Quality Improvement Program (NSQIP) data examined from 2005 to 2013, which also demonstrate a transfusion reduction of $6.1 \%$ over time. ${ }^{7}$ There are other limitations to this study that are well explained by the authors. Perhaps the most notable limitation is that guidelines for intraoperative RBC transfusions are not well established compared with perioperative restrictive guidelines. Thus, when transfusions occur, and by extension whether or not they were indicated, is difficult to discern outside of single-institution analyses. It is also unclear to what extent decreased transfusions are driven by perioperative adherence to guidelines versus a move toward more minimally invasive interventions at centralized facilities over a similar period. The authors are rightfully planning more granular analyses of transfusion appropriateness to guide interventions to further decrease unnecessary transfusions.

While these data confirm gradually evolving practice patterns, one is left to wonder how and why practice change occurs so slowly after conclusive studies are published. Trials supporting restrictive transfusion practices were published in high-impact journals more than 20 years 
ago. ${ }^{8}$ As a result, commissions on overuse and transfusion appropriateness were convened and restrictive guidelines established for approximately the last decade. ${ }^{9}{ }^{910}$ However, recent studies still show substantial and apparently dogmatic practice variation in perioperative transfusion. ${ }^{11,12}$ This is a problem across the medical profession. Our short memories and failure to search for and employ practicechanging studies result in microcosmic practices that vary from one hospital to the next, and even from one surgeon to the next within the same facility. Hospitals without robust quality control infrastructure cannot quickly implement evidence-based practice. This leaves those who wish to follow newer guidelines to fight an uphill battle against the inertia of institutional comfort. What is left is a patchwork of medical and surgical excellence interspersed with, at times, appalling ignorance. Zuckerman and colleagues note several centralized efforts in Ontario that are aimed at educating physicians and supporting hospitals as they adopt guidelines. ${ }^{1}$ These efforts are laudable and certainly affect at least some positive change. Those of us practicing outside of centralized health systems have even fewer resources to affect large-scale positive change. How can we decisively push our fields forward when excellence and innovation appear to permeate surgical practice via Brownian motion?

The case of blood transfusions is an example that is particularly nonsensical. Maintaining a robust blood bank costs money, and transfusions are expensive and timeconsuming. For instance, a single unit of blood transfused at a University of California Los Angeles hospital will generate a US $\$ 1310$ charge (current procedural terminology [CPT] code 36430). ${ }^{13}$ Not surprisingly, restrictive transfusion practices are associated with reduced costs and, more importantly, improved outcomes. ${ }^{14,15}$ So why, with strong evidence and cost drivers, do we still have essentially recreational transfusion practices at some centers or among some practitioners? In the realm of gastrointestinal cancer surgery, practice patterns defy current guidelines more commonly outside of comprehensive cancer centers. ${ }^{16}$ In the US, $<30 \%$ of colectomies for cancer are performed at academic institutions, where they have better reported overall outcomes and are more likely to be comprehensive cancer centers. ${ }^{17}$ Where patients seek treatment is determined by innumerable factors that include reticence to travel, capitated insurance contracts, access to care, and physician referral patterns. In many cases, these patients receive excellent care closer to home, but this is more common in settings with dedicated conscientious teams, and this seems to happen only in places with the right mix of surgeon education and institutional support. ${ }^{18}$ Certainly, the hands of a high-volume private practice surgeon performing a diverse mix of 800 cases per year are likely to be highly skilled, possibly even more skilled than the hands of the academic surgeon performing 200 specialized cases per year. The counterpoint to this is that the 800-case-per-year generalist is much less likely to have the time to seek out and review nuanced literature around a singular disease process. That same high-volume surgeon is still less likely to have time or desire to fight an administrative battle if they wish to change practice patterns for themselves or others. Nevertheless, guideline adherence and other forms of measurable evidence-based care delivery are, in many instances, all we have to benchmark one facility or surgeon against another. This is with good reason as these measures indicate better attention to 'state of the art' care. Even today, we ourselves as surgeons have little more than word of mouth, as purveyed in social media groups or through personal communications, to make ourselves feel better about the surgical care of ourselves or loved ones. When all is said and done, how we disseminate and employ practicechanging studies and guidelines warrants examination at every level if we are to ever achieve equitable delivery of surgical care. In the meantime, let us all agree to think twice before liberally transfusing our hemodynamically stable noncardiac patients who have a perioperative hemoglobin of $>7 \mathrm{~g} / \mathrm{dL}^{2}$

ACKNOWLEDGMENTS Dr. Susanne Warner is an Assistant Professor of Surgery at the City of Hope Comprehensive Cancer Center. She is supported by the generosity of the Natalie and David Roberts Family and also by the American Cancer Society Mentored Research Scholar Grant MRSG-16-047-01-MPC.

\section{REFERENCES}

1. Zuckerman J, Coburn N, Callum J, et al. Declining use of red blood cell transfusions for gastrointestinal cancer surgery: a population-based analysis. Ann Surg Oncol. 2020. https://doi.org/ 10.1245/s10434-020-09291-y.

2. 2. Carson JL, Guyatt G, Heddle NM, et al. Clinical practice guidelines from the AABB: red blood cell transfusion thresholds and storage. JAMA. 2016;316(19):2025-2035.

3. Ontario Network of Transfusion Coordinators.

4. Ontario Regional Blood Coordinating Network.

5. 5. von Elm E, Altman DG, Egger M, et al. The Strengthening the Reporting of Observational Studies in Epidemiology (STROBE) statement: guidelines for reporting observational studies. Int $J$ Surg. 2014;12(12):1495-1499.

6. 6. Benchimol EI, Smeeth L, Guttmann A, et al. The REporting of studies Conducted using Observational Routinely-collected health Data (RECORD) statement. PLoS Med. 2015;12(10): e1001885.

7. 7. Ecker BL, Simmons KD, Zaheer S, et al. Blood transfusion in major abdominal surgery for malignant tumors: a trend analysis using the national surgical quality improvement program. JAMA Surg. 2016;151(6):518-525.

8. Hebert PC, Wells G, Blajchman MA, et al. A multicenter, randomized, controlled clinical trial of transfusion requirements in critical care. Transfusion Requirements in Critical Care Investigators, Canadian Critical Care Trials Group. $N$ Engl J Med. 1999;340(6):409-417. 
9. Carson JL, Grossman BJ, Kleinman S, et al. Red blood cell transfusion: a clinical practice guideline from the AABB*. Ann Intern Med. 2012;157(1):49-58.

10. Callum JL, Waters JH, Shaz BH, Sloan SR, Murphy MF. The AABB recommendations for the Choosing Wisely campaign of the American Board of Internal Medicine. Transfusion. 2014;54(9):2344-2352.

11. Qiang JK, Thompson T, Callum J, Pinkerton P, Lin Y. Variations in $\mathrm{RBC}$ and frozen plasma utilization rates across 62 Ontario community hospitals. Transfusion. 2019;59(2):545-554.

12. Ejaz A, Spolverato G, Kim Y, Frank SM, Pawlik TM. Identifying variations in blood use based on hemoglobin transfusion trigger and target among hepatopancreaticobiliary surgeons. J Am Coll Surg. 2014;219(2):217-228.

13. UCLA Charge List.

14. LaPar DJ, Crosby IK, Ailawadi G, et al. Blood product conservation is associated with improved outcomes and reduced costs after cardiac surgery. $J$ Thorac Cardiovasc Surg. 2013;145(3):796-803; discussion 803-794.
15. Hallet J, Tsang M, Cheng ES, et al. The Impact of Perioperative Red Blood Cell Transfusions on Long-Term Outcomes after Hepatectomy for Colorectal Liver Metastases. Ann Surg Oncol. 2015;22(12):4038-4045.

16. Huang Y-M, Lee Y-W, Huang Y-J, Wei P-L. Comparison of clinical outcomes between laparoscopic and open surgery for leftsided colon cancer: a nationwide population-based study. Sci Rep. 2020;10(1):75.

17. Freischlag K, Adam M, Turner M, et al. With widespread adoption of MIS colectomy for colon cancer, does hospital type matter? Surg Endosc. 2019;33(1):159-168.

18. Gough BL, Levi S, Sabesan A, Abdel-Misih R, Bennett JJ. Complex distal pancreatectomy outcomes performed at a single institution. Surg Oncol. 2018;27(3):428-432.

Publisher's Note Springer Nature remains neutral with regard to jurisdictional claims in published maps and institutional affiliations. 